\title{
The Effect of the Treatment of Crude Tetanus Toxin with Ganglioside Cerebroside Complex on Sphincter Paralysis in the Rabbit's Eye
}

\author{
By JANE MELLANBY AND DIANA POPE \\ Sir William Dunn School of Pathology, University of Oxford \\ AND N. AMBACHE \\ Medical Research Council \\ Royal College of Surgeons of England, London \\ (Accepted for publication 27 August 1967)
}

\begin{abstract}
SUMMARY
Crude tetanus toxin paralyses the cholinergic innervation of the sphincter pupillae of the rabbit eye. To test whether this activity was due to tetanospasmin or to a non-spasmogenic fraction with a peripheral effect, the action of crude tetanus toxin and of the non-spasmogenic fraction prepared from it were compared in rabbits. The paralytic action of the crude toxin was not due to its content of the non-spasmogenic fraction and was probably due to tetanospasmin itself. A convenient method for the preparation of a mixture of the four most abundant gangliosides is given. The preparation of a ganglioside cerebroside complex and its use for the removal of tetanospasmin from a solution of crude tetanus toxin are described.
\end{abstract}

\section{INTRODUCTION}

Ambache, Morgan \& Payling Wright (1948a) showed that I-2 days after injection of a crude preparation of tetanus toxin (13,330 mouse LD 50/mg.; 330 LD 50 per injection) into the anterior chamber of the eye of the rabbit the reflex constriction of the pupil in response to light was abolished; the effect was still produced after sympathetic denervation of the iris. Since stimulation of the oculomotor nerve did not cause constriction of the pupil in the toxin-injected eye and yet the sphincter pupillae would still contract readily (within IO-I 5 seconds) when acetylcholine was injected into the anterior chamber of the eye, it was concluded that the toxin was paralysing the cholinergic innervation of the sphincter pupillae. In further experiments (Ambache, Morgan \& Payling Wright, I948b) it was shown that tetanus toxin decreased the acetylcholine content of the aqueous humour, and to lesser extent of the iris, while leaving the cholinesterase content of the iris unaffected. At the same time, the sphincter pupillae of the intoxicated eye became hypersensitive to carbaminoylcholine injected subcutaneously. It was deduced that the toxin was interfering with the liberation of acetylcholine at the nerve endings in the sphincter pupillae.

Feigen et al. (1963) found that partially purified preparations of tetanus toxin contained a non-spasmogenic fraction (called NSP) which increased the frequency (whilst leaving the amplitude unaffected) of miniature end-plate potentials recorded from intercostal muscles in the isolated hemithorax of the mouse. This is a presynaptic action and so was the paralytic effect of crude tetanus toxin in the eye. It was there- 
fore an obvious possibility that the non-spasmogenic fraction (NSP) might be responsible for the paralytic action of crude tetanus toxin in the eye. The work described in this paper was done to test this possibility; a preliminary account has been published (Ambache \& Mellanby, I966).

The non-spasmogenic fraction from crude tetanus toxin used by Feigen et al. (I963) was prepared by mixing a solution of the crude toxin with a suspension of protagon (a water-insoluble complex of various water-insoluble sphingolipids and water-soluble ganglioside) and then centrifuging off the protagon with the tetanospasmin adsorbed on it. The ability of protagon to fix tetanospasmin is due to its content of ganglioside (van Heyningen, 1959), but pure ganglioside cannot conveniently be used to remove tetanospasmin from a preparation of tetanus toxin since ganglioside, like the toxin, is water-soluble. When, however, ganglioside is complexed with cerebroside it is rendered water-insoluble and can then be used to adsorb tetanospasmin from solution. The capacity of the complex to combine with tetanospasmin is highest when the proportion of cerebroside to ganglioside in the complex is 3: I (van Heyningen \& Mellanby, I 968). In the present work, the action of a crude preparation of tetanus toxin on the rabbit iris was compared with the action of an equal weight of non-spasmogenic fraction prepared by treating the same toxin preparation with ganglioside cerebroside complex. In addition, the action of highly purified tetanus toxin $(60,000,000$ mouse LD $50 / \mathrm{mg}$.) on the rabbit eye was tested.

\section{METHODS}

Toxin preparations. Two preparations of tetanus toxin were obtained from Dr R. O. Thomson of the Wellcome Research Laboratories, Beckenham, Kent. Preparation A was a purified tetanospasmin containing $60,000,000$ mouse LD 50/mg.; preparation B was a fraction, obtained from a saline extract of tetanus bacilli by ammonium sulphate and acid precipitation, containing a relatively high concentration of non-spasmogenic fraction (NSP) and a low concentration of tetanospasmin. It contained I 50 mouse LD 50/mg. The toxins for injection were dissolved in 0.1 M-phosphate ( $\mathrm{pH} 7$ ) containing $0.2 \%(\mathrm{w} / \mathrm{v})$ gelatin (as protective colloid), and diluted appropriately in this buffer.

Assay of toxicity. Serial twofold dilutions of the solutions prepared for the injections were made in $0 . \mathrm{I} \mathrm{M}$-phosphate $(\mathrm{pH} 7)$ containing $0.2 \%(\mathrm{w} / \mathrm{v})$ gelatin; $0.5 \mathrm{ml}$. doses were injected into pairs of Swiss albino mice.

\section{Preparation of non-spasmogenic fraction from crude tetanus toxin}

(a) Ganglioside. Fresh whole beef brain was homogenized in a Waring Blendor with acetone ( $31 . / \mathrm{kg}$.) for $3 \mathrm{~min}$. and the mixture filtered. The residue was extracted again with acetone (I 1./kg. original brain) and dried in a current of air. The dry brain was extracted with chloroform + methanol $(\mathrm{I}+2, \mathrm{v} / \mathrm{v} ; 21 . / \mathrm{kg}$. dry brain $)$ at $60^{\circ}$ with continuous vigorous agitation for $30 \mathrm{~min}$. The extract was filtered off and the residue reextracted with the same volume of solvent. The pooled extracts were left to stand at $4^{\circ}$ overnight. The material which settled out was filtered off and dissolved in chloroform + methanol $(4+\mathrm{I}, \mathrm{v} / \mathrm{v})$. This solution contained about $90 \%$ of the ganglioside but only about $40 \%$ of the total dry weight of the original extract.

Before proceeding to the next stage, the dry weight of the solution was determined and adjusted to $5 \mathrm{~g}$./100 $\mathrm{ml}$. If this solution was not clear it was filtered. Silicic acid 
was added ( $\mathrm{g}$ g./g. dry weight) and the mixture stirred briskly with a glass rod for about $2 \mathrm{~min}$. The suspension was then centrifuged at about $1000 \mathrm{rev} . / \mathrm{min}$. for $15 \mathrm{~min}$. and the supernatant fluid discarded. The silicic acid was washed 3 times with chloroform + methanol $(3+\mathrm{I}, \mathrm{v} / \mathrm{v} ; 8 \mathrm{ml}$./g. silicic acid). The ganglioside was then eluted twice with $8 \mathrm{ml}$. methanol/g. silicic acid. The solution of ganglioside in methanol was then evaporated to approximately one sixth of its volume on a rotary evaporator with bath temperature just below $50^{\circ}$.

The ganglioside was now transferred to an aqueous phase by partition dialysis: the methanol solution was mixed with 2 volumes of chloroform and dialysed (against 2 changes of 20 volumes of distilled water) for $48 \mathrm{hr}$. The upper phase was concentrated on a rotary evaporator to $20 \mathrm{ml}$. for each $\mathrm{kg}$. original fresh brain, and then freeze-dried. The material thus obtained was usually contaminated with a small amount of silicic acid. This was removed by redissolving the material in a small volume of water, centrifuging at $30,000 \mathrm{rev} . / \mathrm{min}$. for $30 \mathrm{~min}$., and freeze-drying the supernatant fluid.

The yield of ganglioside was about $0.5 \mathrm{~g} . / \mathrm{kg}$. fresh whole brain. The sialic acid content varied from 23 to $28 \%$. Ascending thin-layer chromatograms on silicic acid, developed in chloroform + methanol $+2 \cdot 5 \mathrm{~N}$-aqueous ammonia $(60+35+8$ by vol.) and stained with bromthymol blue or Ehrlich reagent, showed 4 ganglioside bands. This was therefore a convenient method for preparing a mixture of the 4 most abundant gangliosides.

(b) Cerebroside. Cerebroside was prepared from beef brain by the method of Carter \& Fujino (1956).

(c) Ganglioside cerebroside complex. Cerebroside and ganglioside were mixed in the proportion of $3: \mathrm{I}$ and dissolved in a mixture of chloroform + methanol $(3+\mathrm{I}$, $\mathrm{v} / \mathrm{v} ; 3 \mathrm{ml} . / \mathrm{I} 00 \mathrm{mg}$. ganglioside) with gentle warming. The solvent was then evaporated off under reduced pressure at $60^{\circ}$ (water-bath temperature). The complex was resuspended in water $(2 \cdot 7 \mathrm{ml} . / 100 \mathrm{mg}$. ganglioside) by stirring with a glass rod, to give a thick white suspension.

(d) Treatment of toxin with the ganglioside cerebroside complex. To a solution containing $12 \mathrm{mg}$. toxin preparation $/ \mathrm{ml}$. in water, 0.25 vol. of the above ganglioside cerebroside suspension was added. The mixture was allowed to stand at room temperature for $5 \mathrm{~min}$. and then centrifuged at $35,000 \mathrm{~g}(20,000 \mathrm{rev} / \mathrm{min}$. in $40 \cdot 2 \mathrm{head}$ of Spinco, Model L) for $20 \mathrm{~min}$. The supernatant fluid was decanted and treated in the same way 3 times with the same amount of ganglioside/cerebroside suspension as before. The supernatant fluid was then freeze-dried and the white powder obtained constituted the non-spasmogenic fraction (NSP) used in this work. This fraction contained $0.6 \%$ of the toxicity (as measured in mice) of the original toxin preparation.

Assay of non-spasmogenic activity. This was done by Dr G. A. Feigen in his laboratory as described in Feigen et al. (1963).

Injection of rabbits. The preparations of toxin or NSP, dissolved in $0.1 \mathrm{M}$-phosphate $(\mathrm{pH} 7 \cdot 0)$ containing $0.2 \%(\mathrm{w} / \mathrm{v})$ gelatin, were injected into the anterior chamber of the eye of albino rabbits as described by Ambache (I95I). In each case, $0.05 \mathrm{ml}$. of solution was injected. Toxin A was diluted so that this volume contained $0.01 \mu \mathrm{g}$. (1000 LD 50); toxin B to contain $25 \mu \mathrm{g}$. (3.75 LD 50); NSP, prepared from B, to contain $25 \mu \mathrm{g}$. in $0.05 \mathrm{ml}$. (0.05 LD 50).

Measurement of pupil diameter. The transverse diameter of the pupil was measured 
by using calipers held just in front of the eye. First, the diameter was measured in diffuse daylight and then the reaction to light was obtained by measuring the pupil diameter again after $30 \mathrm{sec}$. of direct illumination from a $100 \mathrm{~W}$ lamp held $10 \mathrm{~cm}$. from the eye. Measurements were not made during the first day following the injection because during this period the irides sometimes showed signs of vascular engorgement.

\section{RESULTS}

Tetanus toxin was injected into one eye of each of 4 rabbits. In two of these animals the other eye was injected with gelatin buffer and in the other two animals the second eye was injected with the non-spasmogenic fraction. A fifth rabbit was given nonspasmogenic fraction into one eye and gelatin buffer into the other. The diameter of the pupil of each eye was measured at intervals for $4 \mathrm{IO}$ hr after injection, firstly in diffuse daylight and then during direct illumination.

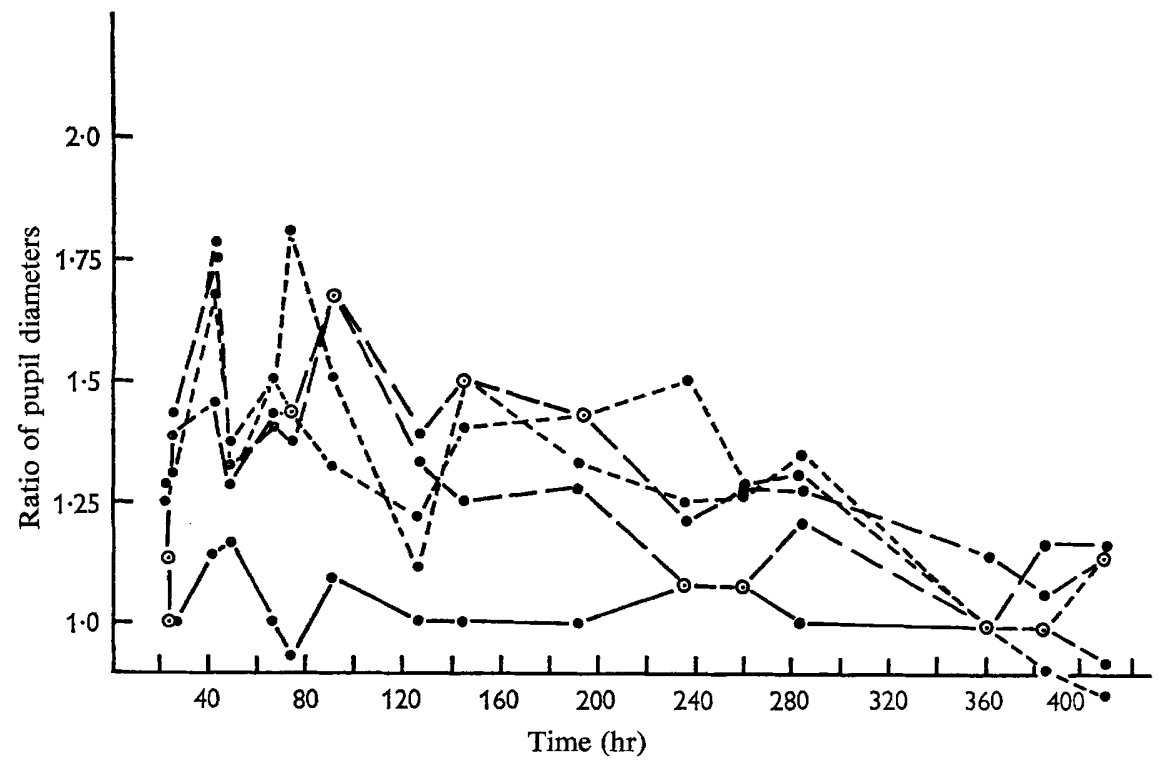

Fig. I. Ratio, in diffuse light, of the diameter of the pupil of the eye injected with either buffer (first and second rabbits, broken lines) or NSP (third and fourth rabbits, dotted lines) to the diameter of the pupil of the other eye of the same animal injected with tetanus toxin, plotted against the time after the injection. The solid line represents the ratio of the diameters of the pupils of the eyes of the fifth rabbit injected on the one side with buffer and on the other with NSP. (For dosages see legend of Table I.)

In Fig. I the results obtained in diffuse daylight are illustrated. The ratio of the diameter of the pupil of each eye injected with tetanus toxin to the diameter of the pupil of the other eye of the same animal injected either with buffer (broken lines) or with NSP (dotted lines) is plotted against the time after the injections. The fifth line (5) represents the ratio of the diameter of the pupils of the eyes of the fifth rabbit which were injected with NSP and buffer respectively. It can be seen in Fig. I that the ratio of the pupil diameters in the animal where NSP was compared with buffer remained around a value of one. On the other hand, the ratios in the rabbits where the effect of tetanus toxin was investigated were always above a value of one. The 
pupil of an eye injected with tetanus toxin and observed in diffuse daylight was around $50 \%$ larger than the opposite pupil regardless of whether that had been injected with buffer only (broken lines) or with NSP (dotted lines). Hence the NSP nolonger possessed the paralytic activity, present in the original crude toxin preparation, which causes an increased pupil diameter observable in diffuse daylight. Figure 2 issimilar to the previous

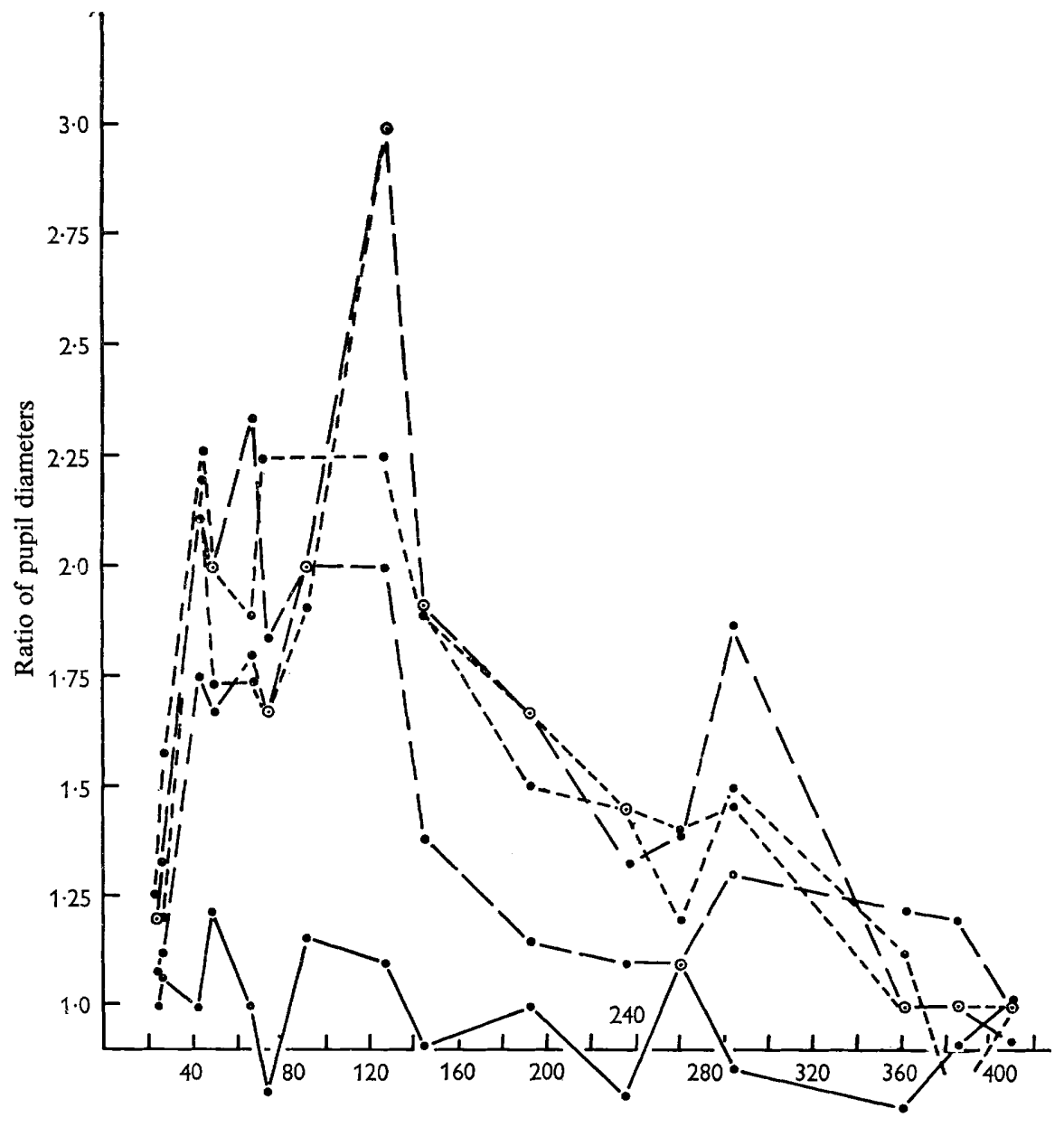

Time (hr)

Fig. 2. Details as in Fig. I, but experiment in direct light from 100 watt lamp held $10 \mathrm{~cm}$. in front of eye.

graph except that here the ratios are derived from measurements of the pupil diameters in direct light. Again, where the ratio is obtained from the animal with NSP in one eye and buffer in the other, the ratio is near to one. In the animals where the ratio is obtained from comparing tetanus toxin injection with either NSP or buffer, the ratios are well above one, and are considerably higher than those obtained in diffuse daylight. Again, there was no difference between the ratios whether tetanus toxin was compared with NSP or with buffer.

The ratios are higher in direct than in diffuse light because the tetanus toxin, but not 
the buffer or NSP, diminished the reflex constricted of the pupil in response to light. This effect is illustrated in Table $I$, where it is shown that over a period lasting from a day or so after injection up to about Io days, tetanus toxin greatly depressed the $\%$ decrease in pupil diameter which occurred in response to direct illumination; neither NSP nor buffer had such an effect. In Table 2 the means (and their standard deviations) are shown for the light response in each of the injected eyes when the values obtained during the period of maximal effect $(42-192 \mathrm{hr})$ are considered. Application of the $t$ test showed that even the response of the eye of rabbit I injected with toxin ( $\mathrm{I} \pm 7 \%$ ) was significantly lower than the response with buffer $(P=0.02)$ and the other three values with toxin injection (rabbits 2-4) were of course more significant $(P<0.005)$. There was no difference between the values with NSP and those with buffer.

The action of highly purified tetanus toxin on the rabbit eye was similar to the action of crude toxin. Thus, $42 \mathrm{hr}$ after injection of $0.0 \mathrm{r} \mu \mathrm{g}$. of purified toxin (rooo mouse LD 50) the reflex response to light in the injected eye was abolished. The response remained absent for about 5 weeks, after which time it gradually returned.

\section{DISCUSSION}

The present work shows that the treatment of crude tetanus toxin with ganglioside/ cerebroside complex, which leaves its non-spasmogenic activity unaffected (or increased) not only removes $99 \%$ of the tetanospasmin but also removes the ability to paralyse the cholinergic innervation of the sphincter pupillae. It can be concluded that the non-spasmogenic factor, able to increase the frequency of intercostal miniature end-plate potentials in a hemithorax preparation from the mouse, is not responsible for the paralysis observed in the eye after injection of tetanus toxin into the anterior chamber. It therefore still remains open for an in vivo action of this non-spasmogenic fraction to be demonstrated.

Since highly purified tetanus toxin had a similar effect to crude toxin, it is likely that this effect in the eye is due to tetanospasmin itself. In the present work with crude toxin the effect on pupil diameter was as great as that obtained by Ambache et al. ( $1948 a$ ) and was produced with approximately a hundredth of the toxicity.

We wish to thank Dr W. E. van Heyningen for advice and encouragement; Dr R. O. Thomson of the Wellcome Research Laboratories for supplying the preparations of tetanus toxin; Dr G. A. Feigen of Stanford University for assaying samples of NSP; Miss Jane Gray for technical assistance. This work was done during the tenure of a contract (Task No. 103-474) between Dr W. E. van Heyningen and the Office of Naval Research of the United States Department of the Navy. 


\section{REFERENCES}

AмвасHE, N. (195I). A further survey of the action of Clostridium botulinum toxin upon different types of autonomic nerve fibre. J. Physiol. r13, I.

Ambache, N. \& Mellanby, J. (I966). Mydriatic action of tetanus toxin. Rep. R. Coll. Surg. p. 65. Ambache, N., Morgan, R. S. \& Payling-Wright, G. (1948a). The action of tetanus toxin on the rabbit's iris. J. Physiol. ro7, 45.

Ambache, N., Morgan, R. S. \& Payling-Wright, G. (1948 $b$ ). The action of tetanus toxin on the acetylcholine and cholinesterase contents of the rabbit's iris. Br. J. exp. Path. 29, 408.

CARTER, H. E. \& FuJINo, Y. (1956). Biochemistry of the sphingolipods. IX. Configuration of the cerebrosides. J. biol. Chem. $221,879$.

Feigen, G. A., Peterson, N. S., Hofmann, W. W., Genther, G. H. \& van Heyningen, W. E. (I963). The effect of impure tetanus toxin on the frequency of miniature endplate potentials. J. gen. Microbiol. 33, 489 .

VAN HEYNINGEN, W. E. (1959). Tentative identification of the tetanus toxin receptor in nervous tissue. J. gen. Microbiol. 20, 310.

van Heyningen, W. E. \& Mellanby, J. (1968). The effect of cerebroside and other lipids on the fixation of tetanus toxin by gangliosides. J. gen. Microbiol. (in the Press) 